well, better in every respect (except reading) than since ber illness commenced. She knitted and worked incessantly, but did not make any atternpt to read or write. Her idea of locality seemed particularly good. Her reading power remained much in statu q7io. On examination she was able to spell out some words, but failed to recognise some of the letters. When a word, however long, was spelt out to her, she at once knew what it was. I remarked to her daughters that her spelling seemed very good, and they immediately said that it was quite unaffected and that they were in the habit of referring to her (as they had been in the habit of doing before she was taken ill) on any doubtful point of spelling. She used to be an excellent speller and still retained her spelling power perfectly, though quite unable to read. When I tested her to-day she failed to read "a" and "not." She said that she thought she could "read, but she was lazy and did not care to do so. Her eyesight was very good and her inability to recognise letters and words was not dne to defective eyesight. There was no change in other respects.

Condition threc years after the onset of the attack - The patient was well all the previous summer, but became duller mentally when the short evenings and cold weather set in. She looked much the same and had not written any letters or attempted to read since the last note.

The patient died four years after the onset of the attack from acute congestion of the lungs and heart failure. There had been no material change in her condition since the last note.

Corrigenda.-Case 1, description of Fig. 1: Instead of "right-sided bilateral temporal hemianopsia," read "rightsided lateral homonymous hemianopsia."-Page 801, lefthand column, thirty-second line from the top, instead of pure" agraphia, read "true" agraphia.

Edinburgh.

\section{AN UNDESCRIBED SYMPTOM IN PERITONITIS.}

BY WILLIAM HENRY BATTLE, F.R.C.S. ENG., asSISTANT SURGEON TO ST. THOMAS'S HOSPITAL AND TO MHE ROYAL FREE HOSPITAL, ETC.

So far as I know, the symptom to whici I wish to call the attention of the profession has not been described in cases of peritonitis, and must accordingly be a very rare one. There is also a probability that this symptom appears in a late stage of the disease, and indicates a very intense inflammation of the peritoneum.

On the morning of Jan. 19th, 1897, I was requested to see, a patient under the care of Dr. Seward in the Colney Hatch Asylum who had developed serious abdominal symptoms. The patient was a man, aged forty-seven years, who had been an inmate of the asylum for three and a half years, suffering from chronic melancholia with a previous history of alcoholic excess. He had had good bodily health until three months before the date on which I saw him; he had then suffered from an attack of brmatemesis of short duration, the cause of which could not be discovered. He had resumed out-door work and appeared to have been in good health until Jan. 12th, when he had another short attack of hæmatemesis. Three days after this he vomited several times and complained of abdominal pain and constipation; his temperature was $101 \cdot 6^{\circ} \mathbf{F}$, and this was the highest registered during his illness. Vomiting continued at intervals, but no further blood was present in the romit; the constipation was unrelieved by enemata, the abdomen became distended, and the pain increased. During the nighs of the 18th the symptoms had become much worse, the vomiting had become much more frequent, and the distension and senderness had much increased. After the despatch of the message to me a condition of collapse set in, and on $\mathrm{my}$ arrival the patient was in a very low state not admitting of opsrative interference. His condition was as follows: $\mathrm{He}$ was lying on his back with his limbs flexed and his head bent forward; he had a sallow, smooth, expressionless face. the eyes and mouth being unduly opened as from muscular weakness; but he was able to understand and answer questions. He was unable to protrude his tongue, which was very dry, beyond the teeth. His extremities were bluish and cold ; respiration was rapid and almost entirely thoracic; the pulse was quick, weak, and very compressible. There was frequent vomiting, which was not feculent, but no passage of fæces or flatus per anum. There was considerable distension of the abdomen, a general tympanitic note on percussion, with much tenderness all over it, but no complaint of pain. This tenderness was most marked in the lower epigastric region, so much so that it caused particular attention to be drawn to the part. It was then found that in both groins, extending outwards to the superior iliac spines, was a symmetrical puffy cedema of the sub-cutaneous tissue; that the odema was limited as regards its downward extension into the thighs by the deep layer of the superficial fascia, the at:achment of which was clearly outlined, and that it passed backwards to a slight extent into the flanks. The skin was somewhat flushed in the groins, and wherever the cedematous condition passed there was excesaive tenderness; the scrotum was œedematous and very tender; there was no cedema of the legs. For the last two days he had had retention of urine which was relieved by catheter; but the urine was normal and the instrument had passed easily. The condition of the patient was becoming rapidly worse, and although it was highly probable that operative treatment was required to relieve his symptoms it was evident that nothing could be done to prevent $a$ fatal termination which was only a question of a few hours. I expressed an opinion that although the symptoms, without the odema of the groins, indicated peritonitis, the presence of the cedema made it certain that such an inflammation was there, whatever might have been the primary disease. At the post-mortem examination made by Dr. Bryan, to whom I am indebted for the following account, the diagnosis of acute peritonitis was fully confirmed.

Necropsy. - The post-mortem examination was made seventeen hours after death. The body was found to be well nourished. With regard to the head the calvaria was normal and the dura mater was normal ; the pia mater was much thickened and stripped easily; the brain substance was somewhat soft, otherwise normal. The vessels at the base were healthy. There was slight hypostatic congestion of the lungs, otherwise they were normal. The heart was healthy; there was slight atheroma of the aorta. As to the abdomen there was an unusual amount of fat, the great omentum being very fatty and the sub-peritoneal fat generally was in great excess. The large intestine from the anus to the cæcum was much distended; there was a hard mass of fæces of the size of a small orange in the cæcum just at the valve, otherwise the large intestine was empty. The appendix was normal. The small intestines were normal throughout except where a small coil dipping down into the pelvic cavity was affected by the peritonitis described below. The mucous membrane of both the large and small intestines was healthy. There was a local acute peritonitis limited above by the crecum and the lower part of the sigmoid flexure, affecting the whole of the pelvic cavity. There were recent adhesions between the rectum and bladder and much recent lymph in the neighbourbood of the cæcum. There was much œdema of the sub-peritoneal tissue, which extended along the inguinal canals on both sides into the scrotum. No cause for the peritonitis could be discovered after a very thorough search, which included an examination of the bones of the pelvis. The liver and stomach were healthy, as were all the other abdominal organs with the exception of the right kidney, which was somewhat pale and which had an appearance of some former inflammatory affection.

Remerris. - The post.mortem examination confirmed the opinion which had been given as to the causation of the unusual condition present during life and also demonstrated the correctness of the explanation which had been offered. Some ten years ago I was called upon to perform an operation about midnight for a parient suffering from acute abdominal symptoms which had commenced when he was straining at stool at six o'clock on the same morning. His condition was very bad and it was impossible to find out what had been the state of his urinary functions before the sudden attack of pain at the time mentioned, but he had been to his work on the previous day and was not known to have been ill. When the abdomen was opened in the middle line the sub-peritoneal tissue contained such an excessive amount of fluid that the possibility of a pathological extra-peritoneal rupture of the bladder suggested itself as the most likely cause for the presence of such an amount in that situation. A sponge saturated with this fluid 
was pronounced by those present to have a distinct]y urinous odour. I myself was unable to express any opinion as a nasal catarrh had taken away my sense of smell. Accordingly the peritoneal cavity was not opened, but a puncture was made in the perinæum and a large catheter passed into the bladder to provide for drainage. The man lived but a few hours afterwards. At the post-mortem examination very acute purulent peritonitis, due to the giving way of a typhoid ulcer, was disclosed. It was not, therefore, a great stretch of the imagination to picture a similar inflammatory exudation as present in this patient, with an escape of some of the fluid along the inguinual canals into the groins, and to a less extent into the scrotum. The comparatively small amount of exudation into the scrotal tissues is probably accounted for by two circumstances(1) the dorsal decubitus of the patient, and (2) the irritating effect of the fluid on the muscular tissue of the scrotum, which was wrinkled as from muscular action of the dartos, and formed a great contrast to the smoothly distended scrotum of the dropsical patient, or that of the sufferer from urinary extravasation. I have mentioned that the cedematous area was excessively tender, to touch it even lightly made the patient start far more than pressure over the abdomen above the level of the extravasation. resembled in this respect the tenderness near the extreme edge of the advancing area in spreading gangrene.

It hardly appears necessary to point out the difference there is between this form of cedema and that due to cellulitis of the scrotum and groins having its origin in some external breach of surface; the limitation of the exudation by the deep layer of the superficial fascia will clearly differentiate the two, as it also excludes any form of dropsy. Its resemblance to extravasation of urine is much more near, but it does not pass into the perineum, and the scrotum in extravasation of urine, where the fluid is at first of a less irritating character, is very much more distended in proportion to the extent of groin extravasation; the penis is also much enlarged, and there is usually a well-marked history of stricture of the urethra, with proof of its presence, whilst there are no symptoms pointing to peritoneal inflammation. If the urethra had given way in front of or under the scrotum the swelling of the penis and scrotum would be in excess of the other portion of the swelling and the stricture signs would be evident, \&c. It is very possible that this condition, although noted, has been ascribed to an exudation through the abdominal wall in consequence of the inflammation of the muscular tissue over a centre of inflammation within the abdomen. It is not unlikely that much of the cedema in cases of localised inflammation about the cæcum has followed the sub-peritoneal tissue in part, and that in an odematous condition of the subcutaneous tissue of the groin the fluid, anticipating the closer approach to the surface of an inflammatory exudation, has really gravitated to that position after its escape from the inguinal canal in consequence of the position of the patient. To say that such a condition as that described does not occur because some observer of known skill has not noted it, recalls an observation to my mind which was made by the President of the Clinical Societiy at a recent meeting; this was to the effect that we could not say that a particular symptom was or was not present in any case, although we might think so, if we had not looked for it. I cannot say that this symptom was not present in the patient to whom I have alluded above, in whom the exudation of fluid into the sub-peritoneal tissue was so excessive, because my attention had not been drawn to the possibility of its occurrence and I dicl not look for it-indeed, the exudation of such an amount of fluid was a surprise to me, but I was informed that a similar exudation of fluid was not uncommonly found in the post-mortem room. If this is the experience of many pathologists, then it is exceedingly probable that the condition to which I have drawn attention is not so uncommon as would at first sight appear to be the case. We have not sufficient data to enable us to form an opinion as to the exact value of this sign, but it is not unlikely that it is one which indicates a more than usually bad prognosis.

Mansfield-street, $\mathbf{W}$.

Wiltshire County CouncrL.-The agricultural committee of the Wiltshire County Council have recommended the appointment of Mr. I. M. H. Munro, D.Sc., F C.S., F.C.I., as district agricultural analyst for the administrative county of Wiltshire.

\section{MEDIASTINAL SURGERY.}

BY H. MILTON, M.R.C.S. ENG.,

PRINCIPAL MEDICAL OFFICEP, KA8R FI AINI HOSPITAL, CAIRO.

THE abdominal and cerebro-spinal cavities and the organs they contain have been freely explored by the surgeon since he has adopted cleanliness with the most brilliant results. The thoracic cavity and its contents, although frequently the seat of surgical interference, have not received the same attention, and no definite lines of technique have so far been laid down. This is partly due to the fact that the thoracic walls present more mechanical difficulties to the surgeon than the abdominal, and partly to the dread with which interference with most of the thoracic organs still inspires him. Having lately met with a series of cases of intra. thoracic disease in which there arose an urgent demand for surgical interference I determined to try to ascertain whether the general cavity of the thorax must of necessity remain a terra incognita to the operating surgeon. Considering the subject in the post-mortem room, the advantages of the median incision-a prolongation, in fact, of the usual abdominal exploratory incision-conld not but strike one. So easy is this incision of execution and so considerable is the power of exploration thereby obtained that one is almost induced to hope that future experience may justify the application to it of the term "normal thoracic incision." $\mathrm{As}$ a commencement of my experiments I opened some tes thoracic cavities of subjects dexd from various diseases, employing, with slight variations, the following method:1. A long skin incision from the thyroid cartilage to the ensiform cartilage. 2. Exposure by rapid dissection. of the trachea down to the notch of the sternum and of the same bone in all its extent. 3 . The separation of the fascia from the notch of the sternum as far outwards as the tendon of the sterno-mastoid on either side, keeping the point of the knife absolutely on the periosteum of the sternum so as to avoid injury to veins, \&c. 4. The separation with the finger tip of the posterior surface of the sternum, just below the notch, from the tissues lying beneath it, these latter being displaced backwards. They consist principally of the innominate vein and artery, the trachea, and many nerve branches and plexuses. 5. An incision with the saw along the middle line of the sternum from notch to ensiform cartilage, not implicating the latter and not quite cutting through the whole thickness of the bone. It is to be noted here that the thickest and hardest portion of the bone is at its upper end. This must be thoroughly divided, the vein and other underlying structures being protected by a finger inserted behind the sternum. 6 . The complete separation of the two halves of the sternum I have carried out in two ways. In some cases I have commenced at the sternal notch, in others just above the ensiform cartilage. The second method has the advantage that the first part of the separation, which has to be done with but a very obscured view of the deeper tissues, takes place at a situation where the mediastinum is wide. There is less danger consequently of wounding the pleura, and by inclining the incision to the left this danger is still more averted. In the operation on the living subject I followed this method, but still I cannow say that I found in my preliminary operations on the cadaver any great superiority of the one over the other method. Whichever method is followed great care is necessary in separatiog the two halves of the sternum to aroid injury of the deeper tissues. In beginning from the lower end of the sternum the ensiform cartilage must be separated first from the sternum. This in young subjects can be done with the knife; in older subjects I have used scisscrs or bone nippers. Strong, broad-hooked retractors are now inserted into the halves of the sternum along the line of incision and moderately firm traction outwards and slightly upwards applied to them. The ensiform cartilage is now thoroughly separated from the sternum. There is but very little possibility of opening the peritoneal cavity in doing this, and even should it occur it is of no importance. With a retractor the tissues lying under the line of separation of the ensiform cartilage and the sternum are now displaced backwards, great care being taken to work quite close up to the posterior surface of this bone. Either with knife or scissors the saw-cut is carried light through the bone, extending upwards to the limit of separation of the deep 